\title{
Atividades experimentais com enfoque no processo de modelagem científica: Uma alternativa para a ressignificação das aulas de laboratório em cursos de graduação em física
}

\author{
Experimental activities with focus on the process of scientific modeling: \\ An alternative for the laboratory classes in physics undergraduate courses \\ Leonardo Albuquerque Heidemann, Ives Solano Araujo, Eliane Angela Veit \\ Instituto de Física, Universidade Federal do Rio Grande do Sul, Porto Algre, RS, Brasil \\ Recebido em 7 de agosto de 2015. Aceito em 17 de outubro de 2015
}

\begin{abstract}
Ainda hoje são frequentes em aulas de laboratório de cursos de graduação em física atividades que levam os estudantes a agir mecanicamente na execução de roteiros excessivamente dirigidos, sem refletir suficientemente sobre os fundamentos teóricos que embasam seus experimentos. Muitas dessas atividades são amparadas em concepções epistemológicas inadequadas, favorecendo a construção, por parte dos estudantes, de concepções ingênuas sobre a natureza da ciência. Frente a esse quadro, faz-se necessário propostas para aulas de laboratório que coloquem os estudantes como protagonistas em suas investigações e que evidenciem aspectos importantes do fazer experimental. Focados nessa necessidade, apresentamos neste artigo quatro atividades, envolvendo oscilações mecânicas, fluidos e termodinâmica, delineadas com o objetivo de ressignificar as atividades experimentais por meio do que denominamos de episódios de modelagem. Nessas atividades, os estudantes são postos frente a situações que: i) evidenciam aspectos importantes do processo de modelagem científica, dando oportunidade para que eles construam concepções epistemológicas não ingênuas, e ii) demandam uma postura ativa, possibilitando o desenvolvimento de competências relacionadas com a criação de questões de pesquisa, o delineamento de experimentos, a execução crítica de procedimentos experimentais e a análise de dados. Espera-se que essas atividades possam inspirar professores e pesquisadores que tenham o intuito de delinear e realizar atividades experimentais que favoreçam o engajamento e a reflexão dos estudantes durante as suas investigações, utilizando conhecimentos científicos para enfrentar problemas sobre eventos reais.
\end{abstract}

Palavras-chave: atividades experimentais, modelagem científica, laboratório de física.

Today, laboratory classes are still frequent in physics undergraduate courses: activities that lead students to act mechanically in the execution of excessively guided scripts, without reflecting enough on the theoretical fundaments that give base to their experiments. Many of these activities are supported by inadequate epistemological conceptions, fostering naive views about the nature of science. In face of this situation, it is necessary to propose laboratory classes that make students the protagonists of their own inquiries and highlight important aspects of the practice of experimentation. With focus on this necessity, we present in this article four activities that involve mechanical oscillations, fluids and thermodynamics. The activities have been designed with the purpose of reframe experimental activities through what we call Modeling Episodes. In these activities, students face situations that: i) highlight important aspects of the process of scientific modeling, giving them the opportunity to construct epistemological concepts that are wise and not naive, and ii) demand an active role of the students, allowing the development of competences related to the creation of research questions, the designing of experiments, the critical execution of experimental procedures and data analysis. We hope these activities may inspire teachers and researchers to design and execute experimental activities that are favor engagement and reflection by the students during their inquiries, allowing them to use their scientific knowledge to tackle real problems originated in real events.

Keywords: experimental activities, scientific modeling, physics laboratory.

*Endereço de correspondência: leonardo@heidemann.com.br 


\section{Introdução}

O editor da revista Physics Today, Charles Day, em recente publicação no blog The Dayside [1], expõe uma reflexão sobre o motivo pelo qual não se tornou um físico experimental. Relata que, quando estudante de graduação em física, no tradicional Imperial College London, cursou disciplinas de laboratório obrigatórias tão entediantes que ele nem mesmo lembra dos experimentos realizados. Fica nítido em seu relato que, em sua formação como físico, Day participou de aulas de laboratório que não lhe trazem boas lembranças, podendo ter contribuído decisivamente para a sua escolha de não trabalhar como físico experimental.

Não há dúvida de que existem estudantes que se adaptam à metodologia de ensino empregada em atividades experimentais tradicionais, desfrutando de boas experiências em suas aulas de laboratório. No entanto, o relato de Day pode ser entendido como mais uma evidência de que a forma como muitas atividades experimentais são desenvolvidas em cursos de graduação em física, muitas vezes com enfoque no preenchimento de tabelas e na construção de gráficos previstos em roteiros fortemente dirigidos, costuma não ser bem aceita pelos estudantes [2-3]. Devido à forma como são estruturadas, essas atividades podem ser realizadas mecanicamente, pois não estimulam os estudantes a refletir suficientemente sobre as construções teóricas que fundamentam os experimentos realizados [3-6]. Em função disso, são frequentemente desenvolvidas dissociadas dos conteúdos abordados nas aulas teóricas de física, favorecendo um ensino dicotomizado, em que teoria e prática são tratados de forma desagregada. Essa dissociação, já denunciada por Feynmann [7] como um dos principais problemas do ensino de física no Brasil, contribui para que os estudantes tenham significativas dificuldades para relacionar teorias e realidade.

O cenário destacado aqui evidencia a necessidade de inserção no ensino de física de atividades experimentais que demandem não apenas a execução de experimentos previamente construídos, mas que também envolvam, em algum grau, a proposição de questões de pesquisa, o delineamento de experimentos e a análise de dados com base em modelos científicos, a coleta de dados experimentais e, por fim, a construção de conclusões a partir de evidências. Nesse sentido, a proposta de Sequências de Ensino Investigativas (SEI), de Pessoa de Carvalho [8-9], fornece uma contribuição importante para o ensino de ciências, preconizando investigações que levem os estudantes a serem protagonistas em suas aprendizagens por meio da procura por respostas para problemas sobre a natureza. No entanto, o enfoque das SEI não é especificamente para o Ensino Superior e grande parte das atividades desenvolvidas com base nesse referencial tem como alvo o Ensino Fundamental e Médio. Nesses casos, não há explicitamente uma maior preocupação com a formalização dos conhecimentos abordados, o que é fundamental no contexto de disciplinas experimentais de cursos de graduação.

Neste artigo, nossa proposta é enfrentar o problema da dissociação teoria-prática em disciplinas experimentais de cursos de graduação em física. Mais especificamente, descrevemos exemplos de atividades que oportunizam avanços nas aulas de laboratório no sentido de superar críticas repetidamente presentes na literatura [3-6], se diferenciando das abordagens tradicionais: a) pelo enfoque dos problemas propostos, delineados com o intuito de proporcionar situações que promovam o enriquecimento das concepções epistemológicas dos estudantes, e b) pelas tarefas incumbidas aos estudantes que, além de não serem detalhadas em um roteiro, envolvem desde a criação de questões de pesquisa pertinentes até a construção de conclusões baseadas em evidências experimentais.

Para isso, expomos a estrutura metodológica e os objetivos das atividades, que denominamos de episódios de modelagem, e, em seguida, as especificidades de quatro atividades sobre diferentes conteúdos de física (oscilações mecânicas, fluidos e termodinâmica) intituladas como: i) Pêndulos, ii) Sistema de Amortecimento Automotivo, iii) Arquimedes e a coroa do rei, e iv) Resfriamento de Sistemas.

\section{Episódios de modelagem: Estrutura metodológica e objetivos}

Os quatro episódios de modelagem propostos neste artigo foram delineados com base na Modelagem Didático-Científica (MDC) [10]. Esse referencial teórico-epistemológico parte da tese de que a modelagem científica pode ser entendida como um campo conceitual subjacente aos campos conceituais específicos da física para propor conhecimentos de referência que os estudantes precisam mobilizar 
quando enfrentam situações que demandam a construção, o uso e a validação de modelos científicos. Desse modo, propor situações que possibilitem que os estudantes desenvolvam esses conhecimentos é um dos objetivos principais dos episódios de modelagem.

Adotando a MDC, nos aliamos aos pesquisadores que defendem que os modelos científicos são os mediadores entre as teorias e a realidade [11-13]. Entendemos que, para resolver problemas sobre eventos reais, que, diferentemente das questões frequentemente abordadas nas aulas de física, são problemas não idealizados, os estudantes precisam ter clareza sobre as simplificações da realidade assumidas nos modelos científicos que constroem e/ou exploram. Decorre daí nossa decisão de, nos episódios de modelagem, buscar envolver os estudantes de física com aspectos centrais do processo de modelagem científica, dando oportunidade para que desenvolvam competências que envolvem desde a construção de representações simplificadas de eventos reais, até a contrastação dessas representações com eventos reais por meio de investigações experimentais. Evidentemente, não é nossa expectativa que os estudantes desenvolvam essas competências em algumas poucas atividades de laboratório. O caminho a ser percorrido até que se tornem aptos a realizar de forma independente as ações necessárias para uma investigação experimental é bastante longo, demandando um tempo muito maior do que o usualmente destinado para uma disciplina de laboratório. Por isso, entendemos que os objetivos de aprendizagem das atividades exemplificadas neste artigo precisam permear muitas das disciplinas ao longo de todo o curso de física.

O enfrentamento e até mesmo a compreensão das situações propostas nos episódios de modelagem demanda dos estudantes o uso de uma série de conhecimentos teóricos e práticos. A fim de mobilizar alguns dos conhecimentos básicos fundamentais para as atividades que desenvolverão, é previsto que, anteriormente à aula, realizem uma tarefa de leitura. Aos moldes do que é proposto na metodologia intitulada Ensino sob Medida [14], que tem alcançado bons resultados em termos do estímulo à leitura antes das aulas por parte dos estudantes [15], é solicitado aos alunos na semana anterior aos episódios de modelagem a leitura de um texto curto, com aproximadamente cinco páginas. Eles enviam ao professor até o dia anterior ao início dos episódios de modelagem suas repostas a um conjunto de três ou quatro questões relacionadas com a leitura sugerida. Essa entrega pode ser realizada eletronicamente, por meio de, por exemplo, uma plataforma de ensino à distância como o Moodle 1 ou de um formulário online construído com o Google Drive ${ }^{2}$ [16]. Esperase então que o professor analise as respostas dos estudantes e que, antes dos episódios de modelagem, faça uma pequena discussão sobre as dificuldades dos alunos nas questões da tarefa de leitura, que pode ser entendida como uma introdução ao episódio de modelagem.

Inspirados nos ciclos de modelagem de Hestenes [17-18], os episódios de modelagem são estruturados em três etapas, quais sejam: i) discussão inicial, ii) investigação e iii) discussão final. Usaremos aqui o episódio de modelagem "Pêndulos" para exemplificar as características de cada uma delas, destacando os papéis do professor e dos alunos nas atividades.

Na discussão inicial o problema a ser enfrentado é compartilhado com os estudantes. A apresentação desse problema, realizada pelo professor a partir dos conhecimentos mobilizados na tarefa de leitura, envolve dois aspectos: i) a problematização das investigações a serem realizadas pelos estudantes e ii) a simplificação dos eventos que motivam essas investigações. Por exemplo, na atividade "Pêndulos", o professor desenvolve uma problematização analisando processos que podem ser melhor compreendidos por meio de estudos sobre pêndulos. São exemplos desses processos: i) a medida da latitude em um ponto da Terra utilizando um pêndulo de Foucault, ii) a procura por petróleo com o uso de gravímetros pendulares e iii) a mensuração de intervalos de tempo com relógios de pêndulo. Após a problematização, é previsto que o professor, em constante debate com os alunos, argumente que investigar o movimento de oscilação de um pêndulo constituído por uma bola suspensa em um fio possibilita melhor entendimento dos processos descritos. Em outras palavras, espera-se que o professor conduza um processo de simplificação dos eventos problematizados em eventos menos complexos, que podem ser mais facilmente manipulados em laboratório, possibilitando uma maior compreensão dos eventos problematizados.

A problematização e a simplificação realizadas pelo professor norteiam o compartilhamento do pro-

\footnotetext{
${ }^{1}$ Disponível em https://moodle.org. Acesso em 20/7/2015.

${ }^{2}$ Disponível em https://www.google.com/intl/pt-BR/ drive/. Acesso em 20/7/2015.
} 
blema a ser enfrentado no episódio de modelagem, que sempre tem enfoque em aspectos do processo de modelagem científica. Na atividade "Pêndulos", é sugerido o uso do modelo de pêndulo simples [19] para representar o movimento de uma bola que oscila suspensa por um fio. Propõe-se então que os estudantes avaliem o domínio de validade desse modelo por meio de investigações experimentais realizadas com o intuito de identificar as condições em que predições de períodos construídas por meio do modelo de pêndulo simples diferem de no máximo $5 \%$ dos períodos de pêndulos reais. O objetivo deste episódio de modelagem é mostrado na Tabela 11, juntamente com os objetivos das outras três atividades descritas neste artigo.

Na segunda etapa dos episódios de modelagem, denominada investigação, os estudantes, organizados em pequenos grupos, realizam investigações experimentais a fim de resolver o problema proposto na discussão inicial. O trabalho é norteado por um guia de atividade em que são apresentados: i) a problematização do episódio de modelagem, ii) conhecimentos científicos básicos úteis para as investigações e iii) opções de investigação. Por exemplo, no guia de atividade do episódio de modelagem "Pêndulos", que pode ser consultado na Ref. [20], são expostos, além da problematização da atividade e de aspectos gerais do modelo de pêndulo simples, três opções de investigação. Em uma delas, por exemplo, é sugerido que os estudantes avaliem o quanto a amplitude de oscilação de um pêndulo real influencia no seu período. Propõe-se que construam um pêndulo e meçam o seu período diversas vezes utilizando amplitudes diferentes em cada uma das medidas. Cabe ressaltar que os estudantes têm liberdade para realizar investigações diferentes daquelas sugeridas nos guias de atividade, desde que elas contribuam para uma melhor compreensão do problema proposto na discussão inicial.

Uma série de materiais e instrumentos são disponibilizados aos estudantes para que delineiem e conduzam suas investigação. Por exemplo, no caso do episódio de modelagem "Pêndulos", sugere-se que sejam disponibilizados fios com distintas elasticidades e densidades, bolas com diferentes densidades e diâmetros, hastes, mufas, sargentos, trenas, réguas, paquímetros, cronômetros, photogates. Não há obrigatoriedade de uso de todos esses materiais (sugestões de materiais a serem disponibilizados nos vários episódios são apresentados na Ref. [20]). Cabe ressaltar que, como as investigações dos estudantes podem ser imprevisíveis, é difícil antecipar todos os materiais que serão necessários, sendo recomendado apresentar opções diversificadas. Mesmo assim, é possível que seja preciso providenciar materiais durante as investigações.

Pequenos quadros brancos (90 cm x $60 \mathrm{~cm})$ são utilizados pelos estudantes para compartilharem suas ideias durante as investigações. O papel do professor nesta etapa é de auxiliar os estudantes no delineamento, na coleta e na análise de dados das suas investigações, auxiliando-os em suas dificuldades e alertando-os sobre os equívocos que possam cometer. Também é papel do professor avaliar o planejamento das investigações dos estudantes, autorizando-os a coletar dados somente após a sua aprovação. Para

Tabela 1: Objetivos gerais dos episódios de modelagem. Os objetivos específicos das atividades podem ser consultados na Ref. [20].

\begin{tabular}{|c|c|}
\hline $\begin{array}{l}\text { Episódio de } \\
\text { modelagem }\end{array}$ & Objetivo Geral: proporcionar situações-problemas para que os estudantes compreendam... \\
\hline Pêndulos & $\begin{array}{l}\text {...o caráter representacional dos modelos teóricos da física, e que o grau de precisão e } \\
\text { o domínio de validade desses modelos dependem das simplificações da realidade consideradas. }\end{array}$ \\
\hline $\begin{array}{l}\text { Sistema de amorteci- } \\
\text { mento automotivo }\end{array}$ & $\begin{array}{l}\text {...que os modelos teóricos da física são construções com o propósito de representar } \\
\text { eventos reais, ou supostos como tais, e que as simplificações da realidade consideradas nesses } \\
\text { modelos influenciam fortemente o delineamento de experimentos, pois procuramos utilizar arranjos } \\
\text { experimentais onde os aspectos desconsiderados no modelo teórico de referência influenciam } \\
\text { minimamente. }\end{array}$ \\
\hline $\begin{array}{l}\text { Arquimedes e a coroa } \\
\text { do rei }\end{array}$ & $\begin{array}{l}\text {...que o ato de medir pressupõe o uso de modelos teóricos auxiliares e que a escolha } \\
\text { desses modelos influencia diretamente na precisão das medidas. }\end{array}$ \\
\hline $\begin{array}{l}\text { Resfriamento de sis- } \\
\text { temas }\end{array}$ & $\begin{array}{l}\text {...que quando o grau de precisão de um modelo teórico é insuficiente os modelos podem ser } \\
\text { modificados por meio de alterações nas simplificações da realidade consideradas e/ou na teoria } \\
\text { geral que o ampara. }\end{array}$ \\
\hline
\end{tabular}


esse planejamento, os estudantes precisam, em algum nível:

- Criar questões de pesquisa;

- Construir ou escolher um modelo teórico de referência para a investigação;

- Delinear um arranjo experimental e procedimentos de coleta de dados;

- Planejar a análise dos dados que serão coletados.

Após a aprovação dos seus planejamentos, os estudantes necessitam, ainda na etapa de investigação:

- Construir os arranjos experimentais delineados;

- Coletar dados experimentais;

- Analisar os dados coletados com base no modelo teórico de referência;

- Avaliar as diferenças entre predições e evidências;

- Construir conclusões com base nas evidências da investigação.

A última etapa dos episódios de modelagem é a discussão final. Nela, os estudantes expõem seus resultados ao grande grupo, utilizando os pequenos quadros brancos que permitem a visualização simultânea dos resultados de vários grupos. O papel do professor nesse momento é de mediador. Cabe a ele: i) criar um ambiente de respeito e colaboração entre os estudantes, incentivando-os a explicitarem suas ideias e raciocínios para que se estabeleçam as bases para o compartilhamento de significados entre os participantes do processo de ensino e aprendizagem, ii) introduzir termos técnicos na medida em que sejam necessários para aprimorar a qualidade do discurso dos estudantes, iii) introduzir novas ferramentas de representação na medida em que os estudantes estiverem preparados para fazer bom uso delas, e iv) promover debates explícitos sobre aspectos relacionados com o processo de modelagem científica, dando oportunidade para que os estudantes evoluam em suas concepções sobre a natureza da ciência. Já os estudantes precisam: i) compartilhar seus resultados com o grande grupo, dirimindo as dúvidas dos colegas e do professor, ii) dirigir perguntas aos seus colegas sobre as investigações realizadas. Deseja-se com isso que os estudantes desenvolvam competências para se expressarem na forma oral, construindo argumentos fundamentados em conhecimentos científicos e em evidências experimentais.

Após os debates sobre as investigações dos diversos grupos, o professor expõe uma solução para o problema enfrentado na atividade, relacionando-a com os resultados obtidos pelos alunos. Na atividade "Pêndulos", por exemplo, o professor apresenta resultados de investigações em que o domínio de validade do modelo de pêndulo simples é avaliado por meio de dados produzidos em simulações computacionais em que são consideradas idealizações e aproximações diferentes das assumidas no modelo investigado. Esses resultados podem ser consultados com detalhes na Ref. [18].

É importante ressaltar aqui que, ainda que tenhamos nos inspirado nos ciclos de modelagem de Hestenes, os episódios de modelagem possuem características que os distinguem. Por exemplo, ainda que os ciclos de modelagem envolvam problemas mais abertos que o usual, possibilitando que os estudantes assumam uma postura mais ativa, eles se aproximam das atividades tradicionais quando, diferentemente dos episódios de modelagem, não colocam os estudantes frente a situações que demandam reflexões explícitas sobre as idealizações e aproximações consideradas nos modelos científicos utilizados. Além disso, apesar de apresentarem um referencial teórico-epistemológico para suas atividades, Hestenes e seus colaboradores não explicitam com clareza como suas atividades possibilitam que os estudantes desenvolvam conhecimentos científicos e habilidades de modelagem para enfrentar situações que demandam a construção, o uso e/ou a validação de representações simplificadas de eventos reais.

Assim como em qualquer atividade de ensino, a avaliação é um aspecto fundamental nos episódios de modelagem. Adotamos o princípio de que a avaliação da aprendizagem deve ser coerente com os objetivos e com os procedimentos de ensino, conforme preconizam Valadares e Graça [21]. Para tanto, construímos, baseados nos objetivos de aprendizagem estabelecidos para cada uma das etapas dos episódios de modelagem, um protocolo de avaliação para ser usado pelos professores na correção dos relatórios experimentais produzidos pelos estudantes. Como pode ser constatado no Tabela 2, esse protocolo é constituído por três colunas. Nas duas primeiras são apresentados, respectivamente, os aspectos dos relatórios aos quais os critérios de avaliação se referem e os próprios critérios de avaliação. A terceira coluna é reservada para que o professor avalie os relatórios em três níveis usando os seguintes símbolos: $\boldsymbol{V}, 1 / 2$, e $\boldsymbol{X}$, conforme considera que o critério foi bem, medianamente ou mal atendido no relatório avaliado, respectivamente. No final do protocolo, é reservado ainda um espaço para que o professor faça comentários ressaltando os aspectos positivos e as deficiências mais marcantes dos relatórios.

É previsto que os estudantes tenham conhecimento do protocolo de avaliação antes dos episódios de modelagem. A opção por realizar tal procedimento é baseada em resultados de pesquisa que evidenciam que protocolos de avaliação possibilitam que os estudantes desenvolvam conhecimentos metacognitivos (para uma revisão da literatura, veja Ref. [22]). Mais precisamente, o conhecimento dos 
Tabela 2: Protocolo de avaliação para os relatórios experimentais dos episódios de modelagem.

\begin{tabular}{|c|c|c|}
\hline Aspecto & Critério de avaliação do relatório & $\begin{array}{l}\text { Avaliação do } \\
\text { professor }\end{array}$ \\
\hline $\begin{array}{l}\text { Objetivo da } \\
\text { atividade }\end{array}$ & $\begin{array}{l}\text { Relaciona o objetivo da atividade com um modelo teórico. } \\
\text { Faz referência somente a grandezas, objetos, relações teóricas ou eventos físicos } \\
\text { previamente definidos no relatório. }\end{array}$ & \\
\hline $\begin{array}{l}\text { Referencial } \\
\text { teórico }\end{array}$ & $\begin{array}{l}\text { Explicita as aplicações de leis e/ou princípios de uma teoria geral na situação física } \\
\text { investigada, construindo um modelo teórico adequado para o experimento realizado. } \\
\text { Não apresenta erros conceituais. } \\
\text { Ressalta as implicações das simplificações da realidade consideradas durante a } \\
\text { aplicação das leis e/ou princípios de uma teoria geral à situação física investigada. } \\
\text { Explicita os objetos reais do experimento realizado que são considerados no mo- } \\
\text { delo teórico adotado, não confundindo objetos com as grandezas utilizadas para } \\
\text { representar suas propriedades. }\end{array}$ & \\
\hline $\begin{array}{l}\text { Procedimento } \\
\text { experimental }\end{array}$ & $\begin{array}{l}\text { Explicita as grandezas que foram medidas. } \\
\text { Explicita os instrumentos de medida utilizados. } \\
\text { Explicita o arranjo experimental utilizado. } \\
\text { Explicita o evento físico investigado. } \\
\text { Explicita procedimentos tomados para se controlar variáveis, ou seja, procedimentos } \\
\text { realizados para que os fatores desprezados pelo modelo teórico adotado influenciem } \\
\text { minimamente os dados experimentais. }\end{array}$ & \\
\hline $\begin{array}{l}\text { Apresentação e } \\
\text { análise dos } \\
\text { dados } \\
\text { experimentais }\end{array}$ & $\begin{array}{l}\text { Explicita como o modelo teórico adotado dirigiu a análise dos dados experimentais. } \\
\text { Utiliza ferramentas de representação (gráficos, tabelas, figuras pictóricas, etc.) para } \\
\text { representar os dados coletados experimentalmente de forma adequada (e.g., explicita } \\
\text { as grandezas representadas nos eixos dos gráficos, escolhe escalas adequadas para } \\
\text { tais eixos, etc.). } \\
\text { Interpreta as representações apresentadas corretamente. } \\
\text { Explicita corretamente as incertezas de medida relacionadas com as imprecisões } \\
\text { dos instrumentos de medida utilizados. } \\
\text { Calcula corretamente as incertezas propagadas das imprecisões intrínsecas dos } \\
\text { instrumentos de medida utilizados. } \\
\text { Interpreta as incertezas de medida dos dados coletados experimentalmente, utili- } \\
\text { zando o número adequado de algarismos significativos para representá-los. } \\
\text { Ressalta as principais fontes de incerteza relacionadas com a imprecisão dos instru- } \\
\text { mentos de medida utilizados. } \\
\text { Ressalta as consequências das simplificações consideradas no modelo teórico adotado } \\
\text { que não foram completamente respeitadas no experimento. }\end{array}$ & \\
\hline Conclusões & $\begin{array}{l}\text { Avalia o modelo teórico adotado no experimento. } \\
\text { Apresenta somente conclusões que contam com amparo de evidências experimentais. } \\
\text { Analisa as possíveis contribuições dos resultados experimentais para a resolução do } \\
\text { problema que norteou a investigação realizada. }\end{array}$ & \\
\hline Redação & $\begin{array}{l}\text { Não apresenta erros ortográficos ou gramaticais. } \\
\text { Não apresenta frases cuja falta de clareza comprometem a sua compreensão. } \\
\text { Está estruturado em seções divididas apropriadamente. }\end{array}$ & \\
\hline comentarios. & & \\
\hline
\end{tabular}

itens sobre os quais serão avaliados possibilita que os estudantes controlem suas ações a fim de alcançar um objetivo pré-estabelecido. Desse modo, usando o protocolo de avaliação, facilitamos a regulação dos processos de aprendizagem, o que também é um princípio da avaliação da aprendizagem proposto por Valadares e Graça.

Além do uso do protocolo do Apêndice A, para avaliar as competências dos estudantes relacionadas com a modelagem científica, espera-se também que, nos episódios de modelagem, os alunos sejam avaliados também em termos de suas competências para explicitar ideias na forma oral, que são essenciais para a formação de bons cientistas. As discussões finais das atividades dão oportunidade para que o professor avalie a capacidade dos seus estudantes de apresentar com clareza o delineamento e a execução de suas investigações assim como de expor suas conclusões com base em evidências. Nessa etapa das atividades o professor pode avaliar também se os seus estudantes desenvolveram concepções não ingênuas sobre a natureza da ciência, promovendo debates sobre o assunto na medida do necessário.

Destaca-se que a realização de episódios de modelagem como os propostos neste artigo demanda maior tempo, dentro e fora de aula, do que o tradici- 
onalmente despendido com um mesmo experimento em disciplinas experimentais. Esse é o preço a se pagar ao dar-se certa autonomia aos estudantes e exigir-lhes desde o delineamento do experimento até a exposição oral de seus resultados. Esse tempo depende substancialmente do nível de conhecimento dos alunos e da maturidade para o trabalho colaborativo com certa independência. A título de ilustração, mencionamos que, em uma turma com sete estudantes que cursavam a segunda disciplina experimental do curso de física [23], foram necessárias aproximadamente quatro horas para o desenvolvimento do episódio de modelagem mais curto (Arquimedes e a coroa do rei) e seis horas e meia para o mais longo (Resfriamento de sistemas), sendo que cerca de 30 minutos eram usados para os debates sobre as tarefas de leitura e as discussões iniciais e 40 minutos para as discussões finais.

Nesta seção, apresentamos as características comuns aos quatro episódios de modelagem propostos neste artigo, usando a atividade "Pêndulos" para exemplificar aspectos centrais dos episódios de modelagem. Nas próximas seções, trataremos de particularidades referentes aos quatro episódios exemplificados. Não é nosso objetivo esmiuçar os procedimentos que o professor e os alunos realizam durante cada uma das etapas dos episódios de modelagem. Esses detalhes podem ser consultados na Ref. [20], onde são disponibilizados também materiais para a realização das atividades, incluindo tarefas de leitura, guias de atividades, apresentações de slides para as discussões iniciais e finais, e sugestões de objetos e instrumentos que podem ser disponibilizados aos estudantes. Neste artigo, nos limitamos a debater os aspectos mais gerais dos episódios de modelagem, destacando como cada um deles tem potencial para: possibilitar que os estudantes superem concepções ingênuas sobre o fazer científico; colocá-los frente a situações que podem dar sentido tanto aos conceitos científicos de diferentes campos da física quanto aos conceitos envolvidos no processo de modelagem científica; e também favorecer o desenvolvimento de competências relacionadas à construção, uso e validação de modelos científicos por parte dos estudantes.

\section{Pêndulos}

O entendimento de que as leis científicas são construídas por meio de generalizações realizadas a partir de um conjunto de observações, que é um dos pilares da concepção empirista-indutivista, é profundamente questionado por filósofos da ciência há bastante tempo [24-25]. No entanto, frequentemente aulas de física geral experimental se sustentam nessa concepção, sendo desenvolvidas atividades estruturadas com o intuito de levar os estudantes a redescobrir leis científicas a partir de dados coletados experimentalmente. Existem casos ainda em que os estudantes são incentivados a realizar um experimento com o objetivo de "provar" empiricamente uma teoria científica, o que também é um grave equívoco epistemológico. De modo diferente, a investigação proposta no episódio de modelagem "Pêndulos" tem como propósito avaliar a adequação de um modelo teórico para representar eventos reais. Mais especificamente, é sugerido que os estudantes avaliem o domínio de validade do modelo de pêndulo simples [19]. Com isso, procura-se salientar aos alunos que os modelos científicos são representações simplificadas, e não cópias especulares da realidade, como uma parcela significativa deles acredita [26-27].

O modelo de pêndulo simples [19] pressupõe uma série de idealizações. O corpo suspenso é considerado pontual; o fio de sustentação, sem massa e inelástico; forças resistivas são desprezadas. É usual, ainda, a aproximação de que o pêndulo simples oscila com pequenas amplitudes, o que possibilita predizer o seu período $T$ pela equação

$$
T=2 \pi \cdot \sqrt{\frac{l}{g}},
$$

onde $l$ é o comprimento do fio de sustentação do pêndulo e $g$ é a aceleração gravitacional local.

Com frequência, as idealizações e aproximações consideradas no modelo de pêndulo simples não são devidamente destacadas no ensino de física. Desse modo, cria-se um contexto que favorece que os estudantes concebam o referido modelo como uma construção teórica que tem como referência imediata a realidade quando, de fato, ele se refere a uma descrição simplificada de eventos reais. Procurando destacar o caráter representacional dos modelos, a atividade "Pêndulos" tem por objetivo avaliar o domínio de validade do modelo de pêndulos simples por meio da contrastação de predições construídas com base na Eq. (1) com dados coletados experimentalmente. O enunciado do problema compartilhado com os estudantes na discussão inicial do episódio de modelagem é exposto abaixo.

Até que ponto podemos dizer que a amplitude de um pêndulo é pequena? Quando podemos dizer que as dimensões do corpo suspenso são desprezíveis? Até que ponto a força de arrasto com o ar influencia no período de um pêndulo? Quando podemos dizer que a massa do fio de sustentação é desprezível?

Nesta tarefa exploraremos o contexto de validade do modelo de pêndulo simples. Para isso, queremos que vocês explorem os limites nos quais a diferença entre o 
período predito por meio do modelo de pêndulo simples e o período de pêndulos reais é menor do que $5 \%$.

Não se espera que os estudantes respondam todas as questões propostas no enunciado da atividade. Tampouco espera-se que eles encontrem uma resposta precisa para as perguntas apresentadas. $\mathrm{O}$ fundamental é que, durante a fase de investigação, os estudantes realizem ao menos um experimento, que pode ser um dos três sugeridos no guia da atividade, com o intuito de coletar dados para serem contrastados com predições construídas com a Eq. (1). Por exemplo, procurando avaliar a influência da amplitude de um pêndulo real em seu período, os estudantes podem construir um pêndulo e medir o seu período de oscilação diversas vezes utilizando amplitudes diferentes. Os períodos mensurados poderão então ser contrastados com o período predito por meio da Eq. (1), possibilitando uma avaliação da amplitude para a qual a diferença entre o período medido e o predito é maior do que $5 \%$.

Os estudantes podem ainda avaliar a influência das dimensões do corpo suspenso sobre o período de pêndulos reais. Para isso, eles podem medir o período de um pêndulo diversas vezes modificando o comprimento do fio de sustentação em cada conjunto de medidas. Desse modo, pode-se comparar as razões entre o diâmetro do corpo que oscila dividido pelos comprimentos do fio de sustentação, que fornecem estimativas de quão razoável é considerar o corpo suspenso pontual em cada um dos casos investigados, com os períodos medidos do pêndulo.

Uma terceira possibilidade de experimento pode ser realizada com o intuito de avaliar a influência da força resistiva do ar sobre o período de pêndulos reais. Para isso, pode-se medir o período de um pêndulo diversas vezes utilizando corpos suspensos com distintas dimensões, variando as suas seções retas. É importante debater em todas as atividades, mas principalmente nesse experimento, sobre procedimentos de controle de variáveis. Por exemplo, se para se alterar a seção reta do corpo suspenso for alterada também a sua distribuição de massa, além da seção reta do corpo suspenso será modificado também o momento de inércia do pêndulo em relação ao seu ponto de sustentação. Desse modo, não será possível avaliar se as variações no período do pêndulo real serão decorrentes de mudanças na seção reta do corpo suspenso ou no momento de inércia do pêndulo investigado. Para controlar o momento de inércia do corpo suspenso, pode-se alterar sua seção reta revestindo-o com bolas de isopor leves, por exemplo. Desse modo, utilizando bolas de isopor muito mais leves do que o corpo suspenso, a alteração da seção reta do pêndulo acarretará em variações desprezíveis no seu momento de inércia.
Os softwares Tracker ${ }^{3}$ e Modellus ${ }^{4}$ podem ser utilizados nos experimentos para, respectivamente, coletar dados experimentais por meio de videoanálises e para emular o comportamento do modelo de pêndulo simples por meio de simulações computacionais. Mais detalhes sobre o uso desses softwares na atividade pêndulos podem ser consultados na Ref. [18].

Nesta atividade, distanciando-se das atividades experimentais que favorecem o desenvolvimento de concepções empiristas-indutivistas ingênuas por parte dos estudantes, propõe-se uma avaliação da adequação do modelo de pêndulo simples para representar eventos reais, possibilitando que os estudantes compreendam que os modelos científicos são representações simplificadas da realidade, e que por isso possuem um grau de precisão e um domínio de validade. Além disso, os estudantes podem compreender que as diferenças entre predições construídas com base em modelos científicos e dados coletados experimentalmente decorrem não apenas da imprecisão dos instrumentos de medida utilizados, mas também das simplificações da realidade consideradas no modelo teórico de referência do experimento. As relações entre os períodos de pêndulos reais e suas amplitudes, dimensões dos corpos suspensos e massas dos seus fios de sustentação são exemplos de conhecimentos da física que os estudantes têm a oportunidade de compreender com maior profundidade com a atividade "Pêndulos". Ademais, eles são postos frente a situações que podem dar sentido a conceitos como, por exemplo, de período, frequência e amplitude, assim como de domínio de validade e grau de precisão.

\section{Sistema de amortecimento automotivo}

O papel dos conhecimentos prévios no desenvolvimento da ciência é amplamente destacado por muitos filósofos [24, 28]. A concepção defendida por empiristas ingênuos de que o pesquisador pode (ou deve) abster-se de suas ideias prévias para conduzir uma investigação experimental, baseando-se exclusivamente em observações, não condiz com o que efetivamente é feito pelos cientistas. Experimentos são sempre realizados com base em conhecimentos já existentes [29]. Analisando especificamente as aulas de laboratório, são os conhecimentos prévios dos estudantes que os tornam capazes ou não de identificar os aspectos chave dos experimentos propostos [30]. Destacando este ponto, Arruda e Laburú [31] argumentam que, "se levarmos nossos alunos para o laboratório e dissermos 'observem!', eles certamente irão perguntar 'observar o quê?"'. Mais preci-

\footnotetext{
${ }^{3}$ Disponível em http://modellus.com. Acesso em 20/7/2015.

${ }^{4}$ Disponível em https://www.cabrillo.edu/ dbrown/ tracker/. Acesso em 20/7/2015.
} 
samente, sem conhecimentos sobre versões didáticas de modelos científicos, os estudantes não são capazes de delinear, executar ou analisar experimentos científicos. Modelagem e experimentação, portanto, são processos profundamente imbricados. Apesar disso, pesquisadores têm identificado dificuldades dos estudantes para reconhecer relações entre a experimentação e o processo de modelagem científica [32-34]. Procurando destacar essas relações aos estudantes, a atividade "Sistema de Amortecimento Automotivo" tem como um de seus objetivos evidenciar que os experimentos científicos são, em maior ou menor grau, executados em meios artificiais delineados com base em modelos científicos e, com isso, destacar o papel dos conhecimentos prévios em investigações experimentais. Especificamente, tem-se o intuito de possibilitar que os estudantes ampliem seus conhecimentos sobre o sistema de amortecimento de automóveis por meio de experimentos delineados com base em um modelo teórico construído para representar o sistema massa-mola amortecido.

Frequentemente, cientistas constroem aparatos experimentais simples com o objetivo de investigar sistemas reais mais complexos. Assim ocorre quando, por exemplo, um cientista produz em laboratório centelhas com um gerador elétrico em um ambiente controlado com o objetivo de investigar o comportamento de raios na atmosfera terrestre. Evidentemente, a complexidade dos aparatos pode variar muito dependendo das questões que se almeja responder e de aspectos relacionados com a infraestrutura disponível.

O objetivo básico deste episódio de modelagem é possibilitar que os estudantes construam aparatos experimentais que os permitam investigar o funcionamento de sistemas de amortecimento automotivos em laboratório. Para isso, é previsto que, primeiramente, os próprios estudantes proponham arranjos experimentais análogos ao sistema de amortecimento de automóveis. Debatendo sobre os arranjos experimentais propostos, o professor sugere então que os estudantes investiguem o comportamento de um corpo suspenso por uma mola que oscila imerso em um fluido para aprofundar seus conhecimentos sobre o amortecimento de osciladores mecânicos para, em uma etapa futura, terem melhores condições de compreender sistemas automotivos. O enunciado do problema compartilhado com os estudantes na discussão inicial do episódio de modelagem é exposto abaixo.

Que características devem ter os componentes do sistema de amortecimento de um automóvel? Como essas características influenciam nesse sistema? Quais os principais fatores que influenciam no amortecimento da oscilação de um corpo suspenso por uma mola que se move imerso em um fluido? Como esses fatores influenciam na oscilação desse corpo? Do que dependem esses fatores?

Para representar o comportamento do arranjo experimental sugerido, propõe-se o uso de um modelo teórico construído com base no objeto-modelo de sistema massa-mola amortecido e na mecânica newtoniana [35], que denominamos aqui apenas como modelo de sistema massa-mola amortecido. Sugerese então aos estudantes que eles, durante a fase de investigação, baseiem-se nesse modelo para delinear experimentos com o objetivo de explorar o comportamento de um corpo suspenso por uma mola que oscila imerso em um fluido. Três opções de experimentos são apresentadas no guia de atividade. Por exemplo, como o modelo de sistema massa-mola amortecido pressupõe que o amortecimento do movimento de um corpo que oscila em um fluido depende das propriedades desse fluido, é proposto que os estudantes realizem medidas das constantes de amortecimento dos movimentos de um mesmo corpo quando ele oscila preso a uma mesma mola imerso em diferentes fluidos, com diferentes densidades e/ou viscosidades.

É previsto que o professor proponha que os estudantes filmem os eventos investigados e, por meio de videoanálises realizadas com o software Tracker, coletem dados da posição do corpo que oscila em função do tempo. Além disso, ele pode sugerir também que os participantes analisem os dados coletados com uma planilha eletrônica, inferindo a curva exponencial que melhor modula a senóide que descreve o movimento do sistema massa-mola amortecido, possibilitando a mensuração da constante de amortecimento desse sistema. Esse procedimento oportuniza a realização de debates sobre o ajuste de curvas a dados experimentais, destacando aos estudantes que não são os dados experimentais que apontam o tipo de curva que deve ser ajustada, como sustentam empiristas ingênuos, mas sim que a escolha da curva a ser ajustada é norteada pelo modelo teórico de referência do experimento.

Outra possibilidade de investigação sugerida no guia da atividade é a realização de um experimento com o intuito de avaliar a influência da constante elástica da mola na qual o corpo está preso no seu movimento no interior de um fluido. Para isso, amparados no modelo de sistema massa-mola amortecido, os estudantes podem medir os períodos dos movimentos de um corpo quando ele oscila imerso em um mesmo fluido suspenso por diferentes molas com constantes elásticas conhecidas. Aspectos relacionados com o controle de variáveis também podem ser debatidos aqui. Por exemplo, é importante que os estudantes utilizem molas que tenham massas 
muito menores do que a massa do corpo suspenso, pois, como o modelo de sistema massa-mola amortecido pressupõe que a mola que sustenta o corpo tem massa nula, não será possível detectar se variações no período de oscilação do corpo investigado são decorrentes de variações na massa ou na constante elástica das molas utilizadas.

Com base nos experimentos realizados, os estudantes podem avaliar a adequação do modelo de sistema massa-mola amortecido para representar arranjos experimentais constituídos por corpos oscilando presos em molas imersos em fluidos. A partir disso, os estudantes podem aprofundar seus entendimentos sobre automóveis, podendo estimar o tipo de sistema de amortecimento mais adequado para eles, as propriedades que possibilitam que eles amorteçam de forma apropriada, e os problemas que ocorrem quando eles não possuem alguma das propriedades preconizadas.

O episódio de modelagem "Sistema de Amortecimento Automotivo" evidencia aos estudantes que os experimentos podem ser delineados com o intuito de aprofundar o entendimento de problemas mais complexos do que os estudados em laboratório. Evidencia também que os experimentos são delineados, executados e analisados com base em um modelo teórico de referência. Além disso, o episódio de modelagem põe os estudantes frente a situações que podem dar sentido a conceitos da física como, por exemplo, de densidade, viscosidade e constante de tempo, assim como a conceitos relacionados com a modelagem científica como os de experimento e de controle de variáveis. Os experimentos também envolvem o uso de conhecimentos de física como, por exemplo, de que o amortecimento do movimento de um corpo oscila preso por uma mola imerso em um fluido depende da densidade e da viscosidade do fluido. A atividade oportuniza ainda a realização de debates sobre as diferenças entre forças de arrasto inercial e de arrasto viscoso.

\section{Arquimedes e a coroa do rei}

Os processos de coleta e análise de dados experimentais são fundamentais no trabalho experimental. Desse modo, é necessário que os estudantes compreendam o significado das incertezas experimentais, entendendo os motivos pelos quais elas são intrínsecas ao processo de medição e interpretando-as adequadamente com base em teorias de incertezas. No entanto, pesquisas têm mostrado que os estudantes têm dificuldades para interpretar a dispersão de conjuntos de dados experimentais [36-37]. Além disso, significativa parcela dos estudantes, quando analisa os resultados de seus experimentos, considera que as predições contrastadas nos seus experimentos são referências absolutas, evidenciando que concebem que os modelos têm o mundo como referencial imediato, sendo cópias especulares da realidade [38-39]. $\mathrm{O}$ episódio de modelagem "Arquimedes e a coroa do rei" foi delineado com o objetivo de salientar os motivos pelos quais diferenças entre predições e dados coletados experimentalmente são inevitáveis. Procura-se destacar que as predições de um modelo teórico são aproximadas, pois os modelos são apenas representações simplificadas da realidade, e não cópias exatas. Além disso, busca-se levá-los a compreender que a imprecisão de um instrumento de medida está relacionada com o modelo teórico que fundamenta o seu funcionamento. Para isso, é solicitado que os estudantes meçam a composição de uma amostra de chumbo e alumínio por meio de dois métodos experimentais fundamentados em diferentes modelos teóricos e que demandam o uso de distintos instrumentos de medida.

O mote desta atividade é a lenda de que Arquimedes, a mando do rei Hieron II de Siracusa, teria concluído que a coroa real, supostamente produzida apenas com ouro puro, continha uma parcela de prata em sua composição. Martins [40] sintetiza tal lenda dizendo:

"A lenda afirma que Arquimedes teria notado que transbordava uma quantidade de água da banheira, correspondente ao seu próprio volume, quando entrava nela e que, utilizando um método semelhante, poderia comparar o volume da coroa com os volumes de iguais pesos de prata e ouro: bastava colocá-los em um recipiente cheio de água, e medir a quantidade de líquido derramado. Feliz com essa fantástica descoberta, Arquimedes teria saído correndo nu pelas ruas gritando 'euréka'! (em grego: 'evidentemente!')".

Historiadores da ciência usam uma série de argumentos para questionar profundamente a veracidade desse relato [40]. De maneira distinta, Giancoli [41] sugere que Arquimedes investigou a coroa do rei Hieron II utilizando outro método. O cientista teria suspendido a coroa em um dinamômetro e comparado a leitura do instrumento quando a coroa estava no ar com a sua leitura quando a coroa estava imersa na água.

Procurando propor uma investigação sobre a plausibilidade da lenda de Arquimedes, é solicitado que os estudantes, partindo de medidas da composição de amostras de chumbo e alumínio realizadas com dois métodos experimentais distintos, analisem a confiabilidade das conclusões obtidas por meio de uma avaliação das incertezas das composições mensuradas. Essa análise fornece subsídios para que os estudantes avaliem também a possibilidade de Arquimedes ter utilizado ou não algum desses métodos. 
Além de promover um debate sobre aspectos relacionados com a história da ciência, esta atividade tem potencial para enfatizar aos estudantes que distintos métodos podem ser utilizados com o intuito de medir uma mesma grandeza física, e que cada um desses métodos envolve diferentes instrumentos de medida cujos funcionamentos são suportados por modelos ou hipóteses auxiliares. Por exemplo, um anemômetro de Robinson tem seu funcionamento fundamentado em um modelo teórico que relaciona a frequência angular das pás do aparelho com a velocidade do ar que o circunda. Outro exemplo é identificado em Aguiar e Souza [42] quando, amparados em um modelo teórico que vincula a temperatura de um corpo com suas dimensões, os autores contrastam experimentalmente a lei de resfriamento de Newton realizando medidas da dilatação térmica de uma barra de alumínio.

Em modelos teóricos auxiliares, assim como em qualquer modelo científico, considera-se uma série de idealizações que, por sua vez, implicam imprecisões nas medidas realizadas com os instrumentos de medida que se sustentam neles. Por exemplo, um termômetro de bulbo tem seu funcionamento baseado em um modelo que relaciona o volume do líquido confinado com a sua temperatura. Parte-se do pressuposto de que a altura desse líquido no bulbo do termômetro é diretamente proporcional à sua temperatura, o que nada mais é do que uma idealização, pois o coeficiente de dilatação de um líquido sofre pequenas variações quando a sua temperatura se altera. Desse modo, a temperatura mensurada com um termômetro de bulbo não é incerta somente em função da imprecisão da leitura do indivíduo que a realiza, mas também porque a temperatura medida é inferida a partir de um modelo teórico auxiliar que contém simplificações da realidade.

O enunciado do problema compartilhado com os estudantes na discussão inicial do episódio de modelagem é exposto abaixo.

Diz a lenda que Arquimedes, a mando do rei Hieron II de Siracusa, teria concluído que a coroa real, supostamente produzida apenas com ouro puro, continha uma parcela de prata em sua composição. Arquimedes teria descoberto o princípio que leva seu nome durante um banho, no qual teria visto o nível da água subir enquanto mergulhava seu corpo nela. Apesar da veracidade de tal relato ser profundamente questionada por historiadores da ciência, o método que Arquimedes supostamente utilizou para avaliar a composição da coroa do rei é utilizado até hoje em bons laboratórios de física.

Nesta tarefa, você deverá:
- avaliar a composição de um objeto que contém chumbo e alumínio por meio de dois métodos experimentais distintos buscando comparar a precisão dos resultados obtidos com cada um deles;

- analisar quais as idealizações e aproximações que foram consideradas no modelo teórico que utilizarás;

- buscar avaliar a plausibilidade física da lenda de Arquimedes.

Para auxiliar os estudantes na busca por uma solução para o problema proposto, o professor pode sugerir que eles deduzam uma equação matemática que relaciona a massa de chumbo na amostra $m_{P b}$ com a massa total $m_{t}$ da amostra, o volume total $V_{t}$ da amostra e as densidades do Chumbo $\rho_{P b}$ e do Alumínio $\rho_{A l}$. Essa equação é exposta a seguir (a dedução dessa equação está disponível na Ref. [43]).

$$
m_{P b}=\frac{m_{t}-\rho_{A l} . V_{t}}{\left(1-\frac{\rho_{A l}}{\rho_{P b}}\right)} .
$$

Analisando a Eq. (2), pode-se concluir que, de posse das densidades do Chumbo e do Alumínio, a inferência da composição solicitada na atividade depende apenas de medidas da massa e do volume da amostra. A primeira dessas medidas pode ser facilmente realizada com o uso de uma balança. Já para medir o volume da amostra, ainda que os estudantes possam utilizar diferentes métodos, o professor deve sugerir que eles escolham usar os dois métodos experimentais já citados nesta seção. No primeiro deles, o objeto investigado é inserido em um recipiente com água e é medida a variação do nível da água no mesmo, que é igual ao volume da amostra. No segundo, o objeto investigado é suspenso em um dinamômetro e é registrada a leitura do instrumento quando o objeto está no ar e quando ele é imerso na água. No segundo, o volume da amostra é inferido a partir da mensuração do empuxo que ela sofreu quando imersa em água. As medidas realizadas com os dois métodos podem ser comparadas, oportunizando uma discussão sobre incertezas de medidas uma vez que é importante se avaliar se os resultados obtidos com os dois métodos são condizentes. Além disso, a análise das incertezas dos dados obtidos propiciará uma reflexão sobre a plausibilidade de que Arquimedes tenha utilizado algum dos dois métodos para medir a composição da coroa do rei Hieron II.

Outro debate que pode ser suscitado na atividade envolve uma análise das idealizações consideradas nos modelos teóricos auxiliares que amparam os dois métodos experimentais explorados. Por exemplo, efeitos relacionados com a presença de pequenas bolhas de ar na superfície da amostra são considerados desprezíveis nas medidas realizadas. Além 
disso, caso seja usado um dinamômetro de mola no segundo método experimental utilizado, é tomado como pressuposto que a elongação da mola do instrumento é diretamente proporcional à força aplicada nela, o que não passa de uma idealização e implica em imprecisões nas medidas realizadas.

A investigação proposta neste episódio de modelagem evidencia aos estudantes que as idealizações consideradas nos modelos teóricos que amparam os procedimentos experimentais influenciam diretamente na precisão dos dados coletados. Evidencia-se ainda que a força de empuxo que age sobre um corpo imerso em um fluido é igual ao peso de um volume de fluido equivalente ao volume do corpo imerso no fluido [44], o que é um conhecimento importante no campo da estática de fluidos. A atividade dá oportunidade ainda para que os estudantes deem sentido aos conceitos de empuxo e de densidade, por exemplo.

\section{Resfriamento de sistemas}

A construção de um modelo científico envolve a escolha de uma série de idealizações e aproximações, assim como de uma teoria geral. Desse modo, dependendo das escolhas realizadas, diferentes modelos podem ser produzidos para representar um mesmo evento real. Apesar disso, pesquisas têm identificado evidências de que uma significativa parcela dos estudantes entende que apenas um modelo pode representar corretamente um evento real [26-27]. O episódio de modelagem "Resfriamento de sistemas" foi delineado com o objetivo de evidenciar aos estudantes que diferentes modelos científicos podem ser construídos com o intuito de representar o mesmo evento real, e que um modelo pode ser expandido com o objetivo de ampliar o seu domínio de validade. Especificamente, é solicitado que os estudantes investiguem o resfriamento de sistemas em eventos que extrapolam o domínio de validade da lei de resfriamento de Newton, refletindo sobre modificações que precisam ser promovidas nessa lei para que ela represente o resfriamento desses sistemas com satisfatória precisão.

A lei de resfriamento de Newton tem como pressuposto básico a hipótese de que as trocas de energia por condução, convecção e irradiação de um objeto com o meio que o circunda são proporcionais à diferença entre a temperatura do objeto e a temperatura do ambiente [45]. Partindo disso, ela prediz que a temperatura de um corpo que resfria decai exponencialmente, se igualando à temperatura do meio circundante após um intervalo de tempo suficientemente longo. As predições decorrentes da lei de resfriamento de Newton, que para alguns podem parecer um tanto intuitivas, não são válidas para alguns eventos. Nesta atividade, um desses even-

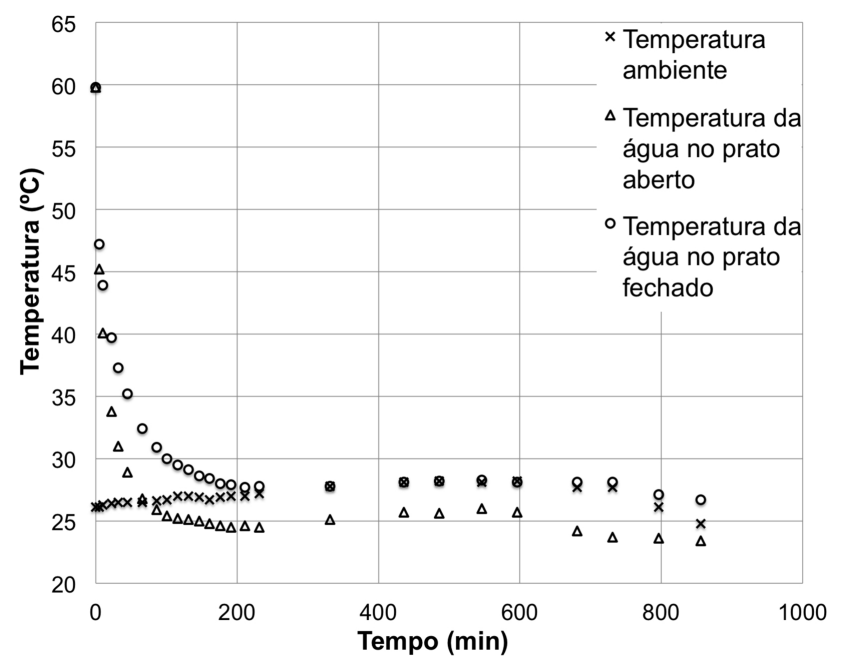

Figura 1: Representação gráfica da evolução temporal da temperatura da água contida em dois pratos (um aberto e um fechado) assim como da temperatura ambiente do local onde tais pratos resfriavam. A água contida no prato aberto atinge uma temperatura menor que a temperatura ambiente.

tos é explorado: o resfriamento de uma porção de água exposta ao ambiente não saturado de vapor d'água. Esse evento não é bem representado pela lei de resfriamento de Newton, pois, nesse caso, devido a perdas de energia por evaporação, a temperatura da água atinge um valor menor do que a temperatura do ambiente que a circunda. $\mathrm{O}$ enunciado do problema compartilhado com os estudantes na discussão inicial do episódio de modelagem é exposto abaixo.

Os dados representados na Fig. $15^{5}$ apresentam medidas de temperatura de dois pratos cheios de água (um deles aberto e outro fechado) em função do tempo. Também é apresentada a temperatura ambiente do local onde o experimento foi realizado.

No dia em que foi realizado o experimento (início de janeiro em Porto Alegre/RS) a umidade relativa era de $70 \%$. O local onde os dois pratos ficavam era próximo de uma janela que estava aberta. Assim sendo, também havia uma pequena corrente de ar no local. Nesta atividade você deverá:

- analisar as diferenças ocorridas entre a evolução temporal da temperatura da água contida no prato aberto e no prato fechado do experimento representado na Fig. 1, identificando os

${ }^{5}$ Dados gentilmente cedidos pelo prof. Fernando Lang da Silveira (IF-UFRGS). 
fatores que explicam essas diferenças e avaliando as modificações que precisam ser efetuadas na lei de resfriamento de Newton para que ela represente com maior precisão o resfriamento da água.

- delinear e realizar um experimento para avaliar a influência dos fatores identificados no resfriamento da água.

Mais do que construir um modelo matemático para representar o evento investigado, espera-se que os estudantes reflitam sobre possíveis modificações que podem ser promovidas na lei de resfriamento de Newton com o objetivo de torná-la mais precisa em suas predições sobre o resfriamento de porções de água. Almeja-se que os alunos tornem-se capazes de apontar fatores que influenciam na taxa de resfriamento da água como, por exemplo, a umidade relativa e a velocidade do ar circundante, a temperatura do líquido e a área do líquido exposta ao ambiente (detalhes sobre um modelo teórico expandido sobre o resfriamento da água podem ser consultados na Ref. [45]).

Entre os experimentos que os estudantes podem realizar, está o uso de um aparato no qual porções de água de mesma massa e mesma temperatura inicial resfriam com diferentes áreas expostas ao ambiente. Comparando a evolução temporal da temperatura e da massa dessas porções, a serem mensuradas no experimento, os estudantes poderão identificar relações entre a área da porção de água exposta ao ambiente, sua taxa de evaporação e sua taxa de resfriamento. Outra possibilidade é avaliar a influência da umidade relativa do ar no resfriamento da água. Para isso, os estudantes podem realizar medidas de temperatura e massa de duas porções de água inicialmente idênticas quando elas são expostas a meios com diferentes umidades relativas. Esses ambientes podem ser preparados com o uso de estufas, (des)umidificadores e/ou aparelhos de ar-condicionado. Os resultados desse experimento possibilitarão que os estudantes compreendam que a taxa de evaporação da água e, consequentemente, a sua taxa de resfriamento são inversamente proporcionais à umidade relativa do meio que a circunda.

Nesta atividade o uso de recursos tecnológicos pode novamente ser explorado. Como é demonstrado na Ref. [45], expansões da lei de resfriamento de Newton que consideram trocas de energia por evaporação podem envolver equações diferenciais que só podem ser resolvidas numericamente. Tais modelos podem ser simulados sem grandes conhecimentos de informática com o uso do software Modellus. Além disso, como é demonstrado na Ref. [46], a placa Arduíno pode ser utilizada para a aquisição automática de dados nos experimentos desta ativi- dade, assim como planilhas eletrônicas podem ser utilizadas para se analisar os dados coletados.

O enfrentamento do problema proposto nesta atividade procura mostrar aos estudantes que um modelo teórico pode ser expandido por meio de modificações nas simplificações da realidade inicialmente realizadas, ou podem alterar o grau de precisão dos resultados teóricos obtidos através do modelo. Além disso, essa atividade torna explícito que diferentes modelos podem ser usados para representar um mesmo evento real. A atividade oportuniza ainda que os estudantes: a) identifiquem fatores que influenciam na taxa de evaporação da água e, consequentemente, na sua taxa de resfriamento; b) deem sentido a conceitos como umidade relativa, temperatura e transferência de energia, fundamentais para a compreensão dos experimentos realizados.

\section{Considerações finais}

Ainda que a experimentação tenha um papel proeminente no fazer científico, o desenvolvimento de aulas de laboratório não se justifica por si só [3-4]. É fundamental que o delineamento das atividades experimentais seja acompanhado de reflexões sobre os motivos pelos quais elas podem auxiliar os estudantes a alcançarem os objetivos de aprendizagem estabelecidos. Além disso, é necessário ainda que a experimentação seja fundamentada em referenciais epistemológicos bem estabelecidos, de modo que as atividades não favoreçam a construção de concepções epistemológicas ingênuas por parte dos estudantes.

O enfoque inadequado das aulas de laboratório tradicionalmente desenvolvidas no ensino de ciências têm suscitado uma série de críticas às atividades experimentais [3-6]. Mais do que apresentar possibilidades de atividades experimentais que podem ser promovidas em disciplinas de graduação, visamos neste artigo inspirar professores e pesquisadores para o delineamento de atividades fundamentadas em concepções adequadas do ponto de vista epistemológico e que possibilitem que teoria e prática sejam tratadas de forma integrada, demandando a reflexão por parte dos estudantes sobre os fundamentos teóricos que amparam as investigações realizadas.

Procuramos demonstrar ainda que é possível inovar no delineamento e na condução de atividades experimentais sem a necessidade de equipamentos modernos ou incomuns. Ao contrário, os episódios de modelagem descritos neste artigo envolvem o uso de arranjos experimentais e instrumentos de medida comuns em laboratórios de física. A inovação está no tipo de problema que é proposto aos alunos e na forma como eles são enfrentados. Buscamos promo- 
ver o engajamento dos estudantes na formulação de questões de pesquisa, no delineamento experimental e na análise de dados, que entendemos ser fundamental para que eles potencializem a aprendizagem durante as aulas de laboratório. Ademais, procuramos com as discussões finais propiciar aos estudantes situações para que eles desenvolvam competências para se comunicar de forma oral, argumentando com base em conhecimentos científicos e evidências experimentais, o que é imprescindível na formação de um bom físico.

Para favorecer esse engajamento, propomos uma metodologia de ensino que coloca os estudantes como protagonistas de suas aprendizagens, possibilitando que eles tenham, em algum nível, liberdade para direcionarem suas ações com o intuito de sanar suas curiosidades. A realização de uma etapa de investigação em que os estudantes procuram resolver um problema que contém um grau de abertura adequado ao nível de ensino dos alunos, como é sugerido nos episódios de modelagem, é uma alternativa para incentivar os estudantes a se engajarem nas atividades, possibilitando que eles sejam ativos nas aulas de laboratório, refletindo sobre como os conhecimentos científicos podem ser mobilizados no enfrentamento de problemas sobre eventos reais.

Foge ao escopo deste artigo apresentar resultados de pesquisa relacionados com o uso dos episódios de modelagem em disciplinas experimentais. No entanto, podemos destacar que nossas investigações $[23,34,47]$ evidenciam que as atividades aqui descritas dão oportunidade para que os estudantes: i) construam atitudes positivas em relação às aulas de laboratório e ii) evoluam em suas concepções sobre a natureza da Ciência. Em linhas gerais, os resultados mostram também que o desenvolvimento das competências dos estudantes relacionadas com o processo de modelagem científica proporcionado por apenas quatro episódios de modelagem é bastante tímido. Esse resultado reforça a concepção de que atividades que coloquem os estudantes frente a situações de modelagem precisam permear muitas das disciplinas do curso de física.

\section{Agradecimento}

Agradecemos aos professores Fernando Lang da Silveira e Mario Norberto Baibich pelas importantes contribuições que tiveram no delineamento das atividades descritas neste artigo. Agradecemos também ao árbitro da RBEF pelas críticas dirigidas ao artigo que em muito contribuíram para a sua melhoria.

\section{Referências}

[1] scitation.aip.org, acessado em 20/7/2015.
[2] H. Kaya and U. Boyuk, European Journal of Physics Education 2, 38 (2011).

[3] D. Hodson, Enseñanza de las Ciencias 12, 541 (1994).

[4] A.T. Borges, Caderno Brasileiro de Ensino de Física 24, 9 (2002).

[5] A. Hofstein and V.N. Lunetta, Science Education 88, 28 (2004).

[6] J. Carrascosa, D. Peìrez, A. Vilches e P. Valdeìs, Caderno Brasileiro de Ensino de Física 23, 157 (2006).

[7] R.P. Feynman, Surely You're Joking, Mr. Feynman! (W.W. Norton \& Company, New York, 1997).

[8] A.M.P. de Carvalho (org.), Calor e Temperatura: Um Ensino por Investigação (Editora Livraria da Física, São Paulo, 2003).

[9] A.M.P. de Carvalho (org.), Ensino de Ciências por Investigação: Condições para Implementação em Sala de Aula (Cengage Learning, São Paulo, (2013).

[10] L.A. Heidemann, I.S. Araujo e E.A. Veit, Caderno Brasileiro de Ensino de Física, no prelo (2016).

[11] J. Gilbert, International Journal of Science and Mathematics Education 2, 115 (2004).

[12] I.T. Koponen, Science \& Education 16, 751 (2007).

[13] P.S. Oh and S.J. Oh, International Journal of Science Education 33, 1109 (2011).

[14] I.S. Araujo e E. Mazur, Caderno Brasileiro de Ensino de Física 30, 362 (2013).

[15] C.E. Heiner, A.I. Banet and C. Wieman, American Journal of Physics 82, 989 (2014).

[16] L.A. Heidemann, A.M. Oliveira e E.A. Veit, Física na Escola 11, 30 (2010).

[17] J. Jackson, L. Dukerich and D. Hestenes, Science Educator 17, 10 (2008).

[18] L.A. Heidemann, I.S. Araujo e E.A. Veit, Caderno Brasileiro de Ensino de Física 29, 965 (2012).

[19] D. Halliday, R. Resnick e J. Walker, Fundamentos de Física - Vol. 2 (Editora LTC, Rio de Janeiro, 2009), $8^{\text {a }}$ ed., p. 95.

[20] L.A. Heidemann, I.S. Araujo e E.A. Veit, Episódios de Modelagem sobre Oscilações Mecânicas, Fluidos e Termodinâmica (Hipermídia, Porto Alegre, 2015). Disponível em http://www.if.ufrgs.br/gpef/ modelagem/hipermidia/ (acesso em 02/08/2015).

[21] J. Valadares e M. Graça, Avaliando para Melhorar a Aprendizagem (Plátano Edições Técnicas, Lisboa, 1998).

[22] E. Panadero and A. Jonsson, Educational Research Review 9, 129 (2013).

[23] L.A. Heidemann, Ressignificação das Atividades Experimentais no Ensino de Física por meio do Enfoque no Processo de Modelagem Científica. Tese de Doutorado, UFRGS, Porto Alegre, 2015. Disponível em http://www.lume.ufrgs.br/handle/ 10183/117767 (acesso em 20/7/2015).

[24] K.R. Popper, Conjecturas e Refutações (Editora Universidade de Brasília, Brasília, 1982). 
[25] P.K. Feyerabend, Contra o Método (Francisco Alves, Rio de Janeiro, 1989).

[26] S.M. Islas y M.A. Pesa, Ciencia, Docencia y Tecnología 29, 117 (2004).

[27] A. Raviolo, A. Aguilar, P. Ramírez y E. López, Revista Electrónica de Investigación en Educación en Ciencias 6, 61 (2011).

[28] M. Bunge, Teoria e Realidade (Editora Perspectiva, São Paulo, (1974).

[29] F.L. da Silveira e L.O.Q. Peduzzi, Caderno Brasileiro de Ensino de Física 23, 26 (2006).

[30] M.A. Moreira e F. Ostermann, Caderno Brasileiro de Ensino de Física 10, 108 (1993).

[31] S.M. Arruda e C.E. Laburú, in: Educação em Ciências: Da Pesquisa à Prática Docente (Editora Escrituras, São Paulo, 1998), cap. 6, p. 53.

[32] M.M. Andrés, M.A. Pesa e J. Meneses, Paradígma 27, 37 (2006).

[33] A. Guillon and M. Séré, in: Teaching and Learning in Science Education (Kluwer Academic Publishers, New York, 2002), p. 121.

[34] L.A. Heidemann, I.S. Araujo y E.A. Veit, Revista Electrónica de Enseñanza de las Ciencias, submetido (2016).

[35] D. Halliday, R. Resnick e J. Walker, op. cit., p. 101.

[36] A. Buffler, F. Lubben and B. Ibrahim, International Journal of Science Education 31, 1137 (2009).

[37] T.S. Volkwyn, S. Allie, A. Buffler and F. Lubben, Physical Review Special Topics - Physics Education Research 4, 010108 (2008).

[38] F. Marineli e J. Pacca, Revista Brasileira de Ensino de Física 28, 497 (2006).

[39] F. Marineli y J. Pacca, Revista Electrónica de Investigación en Educación en Ciencias 9, 13 (2014).

[40] R.A. Martins, Caderno Brasileiro de Ensino de Física 17, 115 (2000), p. 115.

[41] D.C. Giancoli, Physics: Principles and Applications (Pearson Prentice Hall, Upper Saddle River, 2005), p. 265.

[42] C.E. Aguiar e L.F. de Souza, in: Atas do XVIII Simpósio Nacional de Ensino de Física (Vitória, 2009). Disponível em http://www.sbf1.sbfisica.org.br/eventos/ snef/xviii/sys/resumos/T0402-2.pdf (acesso em 20/7/2015).

[43] http://www.if.ufrgs.br/gpef/modelagem/ composicao_amostra.pdf, acessado em 20/7/2015.

[44] F.L. da Silveira e A. Medeiros, Caderno Brasileiro de Ensino de Física 26, 273 (2009).

[45] L.A. Heidemann, I.S. Araujo, E.A. Veit e F.L. da Silveira, in: Atas do XX Simpósio Nacional de Ensino de Física (SBF, São Paulo, 2013). Disponível em http://www.sbf1.sbfisica.org. br/eventos/snef/xx/sys/resumos/T0179-1.pdf (acesso em 20/7/2015).

[46] T. Salvatori, Avaliação de um Modelo sobre o Resfriamento de Líquidos com o uso da Placa
Arduino. Trabalho de Conclusão de Curso de Licenciatura em Física, IFRS (2013). Disponível em http://200.132.6.238:8080/pergamumweb/ vinculos/00001d/00001d50.pdf (acesso em $20 / 7 / 2015)$.

[47] L.A. Heidemann, I.S. Araujo e E.A. Veit, Revista Alexandria, no prelo (2015). 